\title{
New approaches to in-situ heating in FIB/SEM systems
}

\author{
Libor Novák ${ }^{1}$, Min Wu ${ }^{1}$, Petr Wandrol ${ }^{1}$, Miroslav Kolíbal ${ }^{2}$ and Tomáš Vystavěl ${ }^{1}$ \\ 1. Thermo Fisher Scientific, Materials \& Structural Analysis Division, Brno, Czech Republic. \\ 2. CEITEC BUT, Brno University of Technology, Brno, Czech Republic.
}

Over last decades significant effort has been made on in-situ heating experiments inside SEM and FIB/SEM chambers. Traditional way is to use low vacuum environment in the entire chamber. Although this valuable approach brings various undeniable advantages, new state of the art experiments coincide with new requirements, such as rapid changes in temperature, high-vacuum operation to maximize experiment cleanliness, ultra-high resolution SEM imaging and on top of it adaptable geometry in order to investigate sample's crystallography and composition changes using EBSD and EDS detectors. In this contribution we introduce an integration of two new modules fulfilling these requirements by allowing in-situ heating in FIB/SEM systems under high vacuum conditions. Moreover, heating in high vacuum combined with injection of selected gases was also proven capable of providing sample surface oxidation [1] or reduction (Figure 1), [2].

The module choice essentially depends on the sample size and the type of analysis required. For millimeter-sized samples, a bulk heating stage can be selected, which allows a heating rate of unit degrees per second for heating up to $1000^{\circ} \mathrm{C}$. The heating stage is made of materials with negligible outgassing that assures experiment cleanness and can also provide high vacuum environment arround the heated sample with SEM chamber pressure in the order of 10-5 Pa. In-situ observation of microstructure evolution can be achieved by standard SEM detectors collecting SE and BSE signal passing through a user replaceable heat shield, which protects sensitive parts in SEM chamber from overheating. In addition, geometry of a dedicated heat shield permits EBSD mapping as well as EDS analysis of a heated sample placed on this heating stage. However, quality of the EDS and EBSD data is influenced by infrared radiation interference at temperatures above $600^{\circ} \mathrm{C}$. This background can be reduced to minimum by employing a microheatingplate device.

A novel microheatingplate device based on microelectromechanical systems (MEMS) technology provides a maximum temperature of $1200^{\circ} \mathrm{C}$ and a very high heating/cooling rate in the order of $10^{5}$ degrees per second [3]. This MEMS chip is able to support nano-scale to sub-millimeter-sized samples (samples with dimensions in tens of $\mu \mathrm{m}$ are typically used). In-situ imaging of samples placed on the MEMS chip during heating can be obtained using all types of detectors [4] including STEM, EBSD and EDS. The localised heating and small thermal mass capacity bear indespensible merits such as high uniformity of the heating area, high stability even during operations above $1000^{\circ} \mathrm{C}$, site specification and minor sample displacement and drift stablilization. Chunk samples (typically metallic samples for Materials Science research) can be first fabricated using FIB milling in the bulk, then in-situ lifted out, welded on the MEMS chip and optionally the sample surface can be cleaned with low $\mathrm{kV}$ ions. We present in Figure 2 EBSD results of microstructure evolution of a slightly deformed Ti6Al4V chunk sample obtained during in-situ heating at $1100^{\circ} \mathrm{C}$ on MEMS Heating System in an FEI DualBeam Helios G4 work station equipped with standard EBSD detector. 


\section{References:}

[1] T. Kazda, L. Novák, T. Vystavěl, J. Stárek, J. Vondrák, Microsc. Microanal. 22 (Suppl. S3) (2016), p. 1380

[2] M. Kolíbal, T. Pejchal, T. Vystavěl, T. Šikola, Nano Lett. 16(8) (2016), p. 4880

[3] L. Mele et al., Microscopy Research and Technique 79 (2016), p.239

[4] L. Novák, J. Stárek, T. Vystavěl, L. Mele, Microsc. Microanal. 22 (Suppl. S3) (2016), p. 184

[5] The authors acknowledge funding from the Technology Agency of the Czech Republic, TE01020118
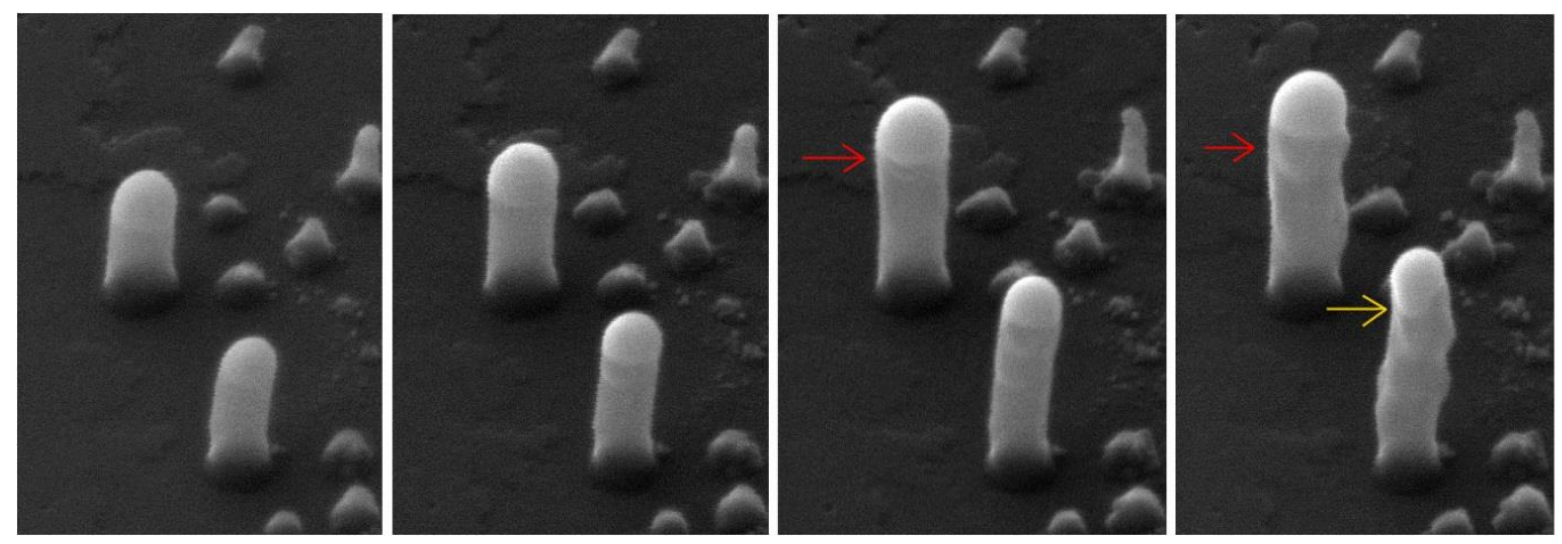

Figure 1: A sequence showing the in-situ growth of Ge nanowires on Ge substrates at high temperature $\left(385{ }^{\circ} \mathrm{C}\right)$ under different vacuum conditions. First two images were taken during growth in atomic hydrogen $(\mathrm{p}=5 \mathrm{e}-3 \mathrm{~Pa})$, while the other two at high vacuum after hydrogen pump down. Real time SEM allows the observation of different processes during growth, e.g. bulge formation in high vacuum (red arrows) and droplet instability (yellow arrow). The images were taken in 30 minute intervals; the horizontal field width is $500 \mathrm{~nm}$.
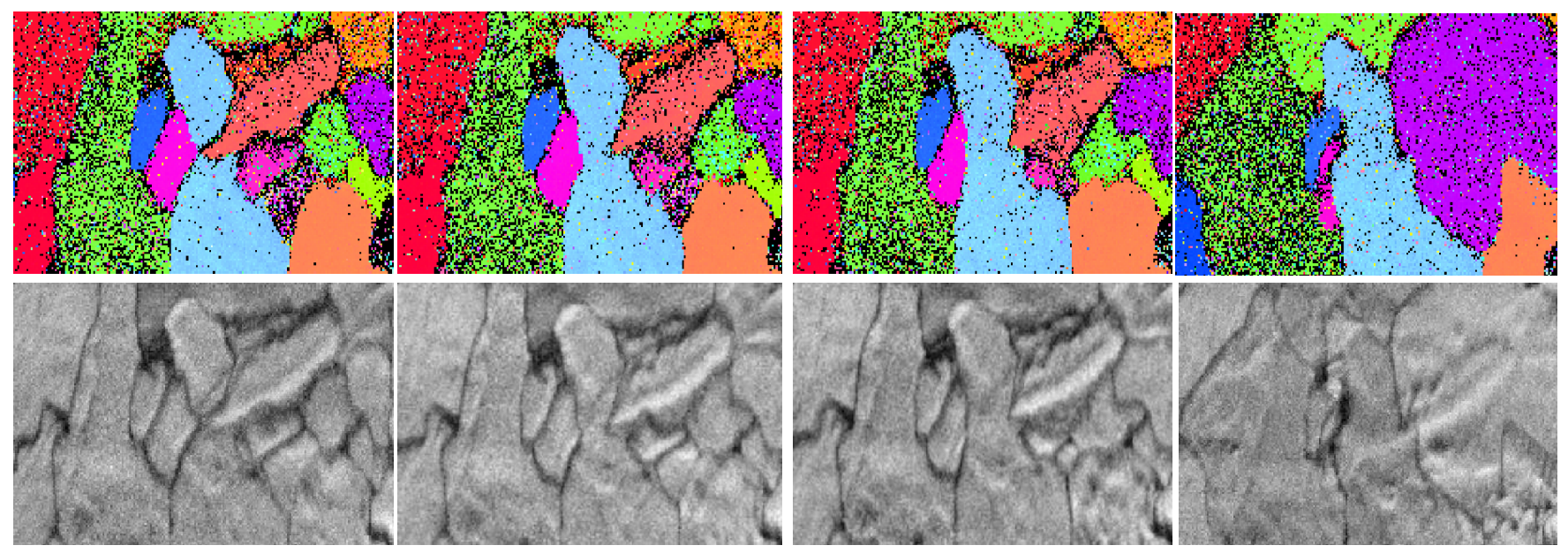

Figure 2: Sequence of 4 EBSD IPFZ images (top row) and corresponding IQM (bottom row) of deformed Ti6Al4V alloys, obtained at $1100^{\circ} \mathrm{C}$ using in-situ MEMS heating. The first three columns of images were taken in 5 minutes intervals, while the last column of images was taken after 50 minutes. The horizontal field width is $20 \mu \mathrm{m}$. 